\title{
Sensibilização em solos: compreensões sociais do recurso solo por um grupo de alunos da Escola Especial Antônio Francisco Lisboa
}

\author{
Environmental awareness: social understanding of soil resource by a \\ group of students from Special School Antônio Francisco Lisboa
}

\author{
Ana Paula Rampelotto ', Ricardo Simão Diniz Dalmolin "
}

\begin{abstract}
RESUMO
As ações antrópicas tem alterado as propriedades do solo e suas composições causando desequilíbrio e ameaçando a existência de diferentes formas de vida, uma vez que o solo possui diferentes funções mantedoras do equilíbrio no planeta e que todos temos direito a Educação Ambiental, é que surge a preocupação em compartilhar essa temática em instituições de atendimento especializado. Esse trabalho procurou compartilhar informações sobre o solo e a natureza com os alunos da Escola Especial Antônio Francisco Lisboa (Santa Maria -RS) com intuito de demonstrar que suas experiências do cotidiano se entrelaçam as questões ambientais. Assim valorizando o interesse dos alunos, por meio de oficinas, foram apresentadas situações distintas que expressaram a importância Da educação ambiental, utilizando o elemento solos. Nessas situações percebeu-se como a educação ambiental é importante e capaz de incluir diferentes públicos na busca do cuidado de si, do outro, do solo, da natureza.
\end{abstract}

Palavras-chave: Educação Ambiental; Solos; Inclusão.

\section{ABSTRACT}

Anthropic actions have altered the properties of the soil and its compositions causing imbalance and threatening the existence of different life forms,since the soil has different balance - keeping functions on the planet and we all have a right to environmental education,the concern arises in sharing this theme in specialized care institutions. This work sought to share information about the soil and nature with the students of the School Special Antônio Francisco Lisboa (Santa Maria, RS) in order to demonstrate the interest of the students, we propose workshops, with different situations, were presented the importance of environmental education, using soils. It was realized how important environmental education is important to include different people in the search for the care of oneself, of the other, of the soil, of nature.

Keywords: Environmental education; Soils; Inclusion.

' Especialista em Educação Ambiental, Pedagoga e Técnica em Meio Ambiente, UFSM. E-mail: anapaular2@hotmail.com. ORCID: https://orcid.org/0000-0001-5962-799X.

" Doutor em ciência do solo, Departamento de Solos, UFSM. E-mail: dalmolin@ufsm.br. ORCID: https://orcid.org/00000002-8834-9869. 


\section{INTRODUÇÃO}

Apesar da Educação Ambiental estar presente nas diversas legislações educacionais e representar uma conquista histórica, percebe-se que estas normas ainda não contemplam a inclusão da Educação Ambiental em todos os níveis e modalidades de ensino e a contemplação dos mais distintos públicos. A Lei nº 9.795, insere a Política Nacional de Educação Ambiental e considera obrigatória a inclusão da temática ambiental em sistemas pedagógicos formais e não-formais.

Há inúmeras formas de trabalhas temáticas que vão ao encontro da educação ambiental (PERES et al. 2018; PEREIRA e BENATTI, 2019). Uma delas é a Educação em Solos, termo definido por Muggler et al (2006) como indissociável da Educação Ambiental, uma vez que o solo é um dos principais componentes do ambiente e responsável conforme Dalmolin e ten Caten (2015) por diversos serviços ambientais fundamentais à manutenção da vida. O solo é a base para a produção de alimentos, fibras e combustível, abriga $25 \%$ de toda a biodiversidade e regula cheias e secas, servido como um amortecedor nas questões climáticas Inúmeros trabalhos encontrados na literatura abordam a temática solo como instrumento de educação ambiental em escolas de ensino fundamental e ensino médio, demonstrando que com as atividades propostas há um aumento no processo ensino-aprendizagem facilitando o entendimento de conceitos básicos relacionados ao ambiente e a importância de sua preservação (WEBER et al. 2017; CANEPELLE et al. 2018). Entretanto, não encontramos nenhum trabalho que aborde a temática sensibilização em solos com alunos com necessidades educativas especiais. No que se refere às políticas públicas que trabalham a educação ambiental em contextos de classe especial, a Lei 9.795/99 dispõe inserção deste público em vivências ambientais para que se (re) pense práticas cotidianas que possam vir a inferir a manutenção da vida na terra. Assim, surgiu da necessidade de trazer a Educação Ambiental para os mais distintos níveis e modalidades de ensino com a finalidade de trazer visibilidade às 
vivências ambientais deste grupo que muitas vezes são desconsideradas pela sociedade.

Considerando as inúmeras situações de degradação do solo que são causadas pela sociedade e que impactam diretamente na manutenção da vida na terra, se faz pertinente evidenciar a importância da temática "sensibilização em solos" para os mais distintos grupos (OLIVEIRA, MARQUES e PAES, 2017). Dentre eles está o público alvo da educação especial, para que haja o compartilhamento e a ressignificância das vivências que cada um tem de modo a formar um plural de experiências com o potencial de desafiar os educadores a trazerem para os espaços formativos (formais ou informais) os questionamentos ambientais. Assim, pode-se refletir como cada um percebe o recurso solo, trazendo contribuições educativas que garantam a inclusão da classe especial nesse contexto, bem como agregar ao campo do conhecimento maneiras diferenciadas de se trabalhar o cuidado e essencialidade do recurso solo e as diferentes formas de vida.

Diante do exposto, esse trabalho expressa a necessidade de apresentar como o público alvo da educação especial se relaciona com o recurso solo e quais contribuições e desafios trazem para o campo da educação ambiental.

\section{MATERIAL E MÉTODOS}

Esse trabalho foi realizado a partir da abordagem qualitativa (BOGDAN E BIKLEN, 1994), sustentado pela observação participante, com delineamento metodológico adaptado por Gil (2008) e Valladares (2018). O estudo foi realizado junto aos alunos e demais membros da Escola Especial Antônio Francisco Lisboa, na cidade de Santa Maria, Rio Grande do Sul. A instituição está localizada no perímetro urbano, não possui fins lucrativos e prima por um atendimento pedagógico especializado conforme portaria 22204/79 que se consolida através de um trabalho integrado entre as áreas da educação, saúde e assistência social. O critério motivador para escolher 
este espaço, foi o fato de a instituição atender o público alvo da educação especial em turmas que abordam as questões ambientais por intermédio de oficinas com reuso de materiais como palha, filtro de café, cds, garrafas pets, entre outros.

Participaram deste trabalho, 12 pessoas, sendo três professoras da instituição (aqui nominadas como E, S e B) e nove alunos com idade entre 20 e 60 anos, em sua maioria mulheres (aqui nominados como J, G, R, E, JA, A, P, Ja, Gu, PR., P ). Os alunos apresentaram uma Classificação Internacional de Doenças e Problemas Relacionados à Saúde (CID) distintos, incluindo F70; 79.9; F79 juntamente com distúrbio de conduta e emoção;71.1; F71; F72; sem diagnóstico, Q43.1, atraso no desenvolvimento neuropsicomotor, fase incomum e bolsa de colostomia, A90, e G40.3 ,F 72.1 e histórias de vida muitas vezes marcada por sequelas físicas e emocionais. Este trabalho procurou evidenciar através de oficinas como cada pessoa enxerga a sua função no meio ambiente.

A primeira etapa do trabalho compreendeu uma abordagem teórica sobre os principais tipos de solos, a importância do solo e sua relação com o ambiente para os estudantes e professores, realizadas por um profissional da área de Ciência do Solo.

Os trabalhos foram divididos em dois períodos: o período 1 (composto pelo momento 0 , pelo momento 1 e momento 2) e o período 2 (composto pela Oficina 1 Soloterapia, pela Oficina 2 - Composteira e pela Oficina 3 - Jogo). Cada situação foi previamente pensada no sentido de organizar tempos e espaços para que os alunos pudessem compartilhar as vivências ambientais do cotidiano e de que forma contribuir para a preservação e cuidado em relação ao recurso solo

Momento 0: Explanação do projeto a diretora da instituição, análise de prontuários e do PPP e observações em sala de aula.

Oficina 1: Soloterapia - Além de uma conversa sobre a importância do solo para o ambiente e para a manutenção da vida, esta oficina foi pensada para os alunos pudessem ter uma interação com o elemento solo. Foi demonstrado como fazer tinta 
de solo (CAPECHE, 2010) e como estas tintas poderiam representar em papel suas vivências em solos. Esta oficina, chamada soloterapia, envolveu a situação inicial de apresentação dos diferentes tipos de solo (perfil e partes sólidas de diferentes cores em vários frascos) no qual os alunos puderam interagir com os materiais e ajudar a fazer a tinta. Discutiu-se, nesse momento sobre a importância do solo em seus diferentes usos e funções, dentre eles a tinta que pode ser usada em paredes de alvenaria, internas ou externas, sem oferecer risco algum ao meio ambiente.

Oficina 2: Composteira. Foi construída, junto com os alunos, uma composteira utilizando potes de sorvete com furos, solo, filtros de café picados e resíduos orgânicos não cítricos. Discutiu-se sobre o uso adequado do solo e qual o papel do solo na decomposição de resíduos orgânicos. Nesta oficina foi apresentado um solo com minhocas e mensurada a importância do solo como abrigo para diferentes tipos de animais (micro e meso fauna). Abordamos com ênfase as minhocas, a qual nesta oficina chamamos de "engenheiros do ecossistema", e suas funções na decomposição dos resíduos e enriquecimento do solo. O solo "enriquecido" foi utilizado para adubar as plantas que estavam em vasos cultivados pelos alunos.

Momento 1: Discussão em grupo sobre a composteira, solo, minhocas e uso do solo enriquecido para adubar as plantas.

Oficina 3: Ludoterapia em solos: A proposta foi pensada levando em consideração o interesse dos alunos por jogos e assim com a ludicidade da proposta apresentar informações sobre os processos de formação do solo e ações humanas que podem vir a impactar o meio ambiente de forma positiva ou negativa. Apresentamos um jogo de tabuleiro onde a minhoca, sai da rocha e percorre um caminho, onde acontece a transformação da rocha em solo, passando por situações favoráveis (avançar casas) e outras nem tanto (voltar casas). Essa proposta previa atrelar o cuidado com o solo, com diferentes usos e funções e a forma como a sociedade aborda as questões ambientais. 
Momento 2: Diálogo com as professoras que acompanharam o grupo de alunos e com diretora da instituição sobre o trabalho desenvolvido.

Esse trabalho obedeceu às normas éticas da UFSM.

\section{RESULTADOS E DISCUSSÃO}

Todas as oficinas e momentos acerca dos usos e funções do recurso solo foram pensados partindo do interesse dos alunos observados nas várias visitas realizadas a instituição.

Na oficina 1, propusemos um momento de exploração de tinta, de cores e de texturas em diferentes tipos de papéis. Em cada desenho a demonstração de aspectos do meio ambiente em suas relações intrínsecas com o ser humano. Por trás de cada minucioso traçado recheado de detalhes, de tinta e papel, estava uma pessoa com sua história vivendo um momento terapêutico, que ia muito além dessa situação. Entre as formas mais sensíveis de expressar os sentimentos está a arte, que para (DONATO, 2012), traz a possibilidade de promover momentos que despertem nas pessoas a sensibilidade com as causas da humanidade bem como a consciência do papel que cada um ocupa enquanto agente transformador.

Percebemos que essa situação provocou certo relaxamento e conexões entre os participantes e as situações ambientais, através de relatos cotidianos mensurados ao longo da oficina e com o passar dessa. Dos minuciosos traços na folha de (J.), das conversas de (G.) com os colegas sobre as cores, da preocupação em "acertar" de (R.), aos relatos de (E.) sobre as possibilidades de uso da tinta de solos e as diferentes formas de uso do solo e até o relato de (J.) sobre a fabricação de panelas (J.) . Há muitos relatos e vivências pessoais perpassadas pela arte, esta que de acordo com (VYGOTSKY, 2004) faz as pessoas sensíveis permitindo exprimir desejos, sentimentos e fantasias desde o nascimento. 
Na oficina 2, a montagem da composteira, apresentou o uso do solo como abrigo. Ao manipular os diferentes recursos e materiais para a composteira surgiam alguns comentários e relações com outros tipos de resíduos encontrados na natureza que fazem menções as vivências cotidianas e um enorme interesse por parte dos alunos de propagar atitudes que buscam o cuidado com o meio ambiente. Nos seguintes comentários: "Casas de laranja, pode?", "E de beterraba?", a sutileza do cuidado com as minhocas, através do aprendizado do que ela consegue degradar sem afetar a sobrevivência e a conservação do solo.

Da sensibilidade do toque as vivências ambientais de cada dia relatadas em: “Eu não pego sacola no mercado quando estou com bolsas", "Posso usar os filtros de café da minha casa para fazer uma composteira?", "Cascas de laranja é cítrico, não pode usar na compostagem", ou seja, nas associações que fizeram em relação aos resíduos que podiam ou não ser utilizados na composteira e também na percepção de um trabalho não valorizado por trás de descartes de resíduos sólidos. Essa situação levou a percepção que para além dos muros da instituição, existe por parte destes alunos uma preocupação com a natureza e com as relações humanas.

Nesses inúmeros momentos, ao longo do trabalho, percebeu-se o quanto as vivências de cada um iam se costurando às propostas e se carregando de significados a cada troca de experiências acadêmicas ou não. Oliveira e Viana (2008) defendem uma abordagem transdisciplinar em educação como um caminho para superar fragilidades, pois esse processo permite conhecer a realidade, as histórias de vida, as percepções, as experiências, as representações e os significados que cada um atribui ao meio ambiente e que são fundamentais na inclusão e valorização de diferentes formas de conhecimento, bem como na proteção da natureza.

Em cada troca de experiências com a turma procurou-se pesquisar os interesses dos alunos e cruzar com temática desse trabalho: "sensibilização em solos", foi assim que surgiu a ideia do jogo de tabuleiro (oficina 3) que conforme fossem 
jogando iriam obter mais informações sobre os processos de formação do solo e ações humanas que podem vir a impactar o meio ambiente de forma positiva ou negativa

$\mathrm{Na}$ maior parte do tempo o jogo representou momentos de diversão e integração do grupo, permeando também alguns momentos em que "termos abstratos" se entrelaçavam e se reportavam a espaços do cotidiano, e a construção e cuidados da composteira. Nesse sentido o jogo (KISHIMOTO,2011) é um importante aliado no desenvolvimento social, afetivo e das funções sensório-motoras.

No decorrer destas intervenções dentro e fora da sala de aula notou-se o quanto as propostas foram significativas para os alunos que seguidamente relacionavam estas práticas com as vivências cotidianas. Santos e Benevides, (2015) apontam para a necessidade de pensar uma abordagem que valorize os saberes já existentes, adquiridos por cada pessoa, agregando estes a novos saberes, afim de formar cidadãos mais conscientes da importância do solo para a vida.

Em relação as professoras que acompanharam o grupo, S. relatou que nunca antes a instituição recebeu uma proposta em Educação Ambiental vinda de outra instituição e evidenciou a necessidade de trazer para estes espaços, momentos que contribuam positivamente para a formação das pessoas que frequentam a instituição. Foi destacada a maneira sútil de como foi apresentada a importância do solo para as mais distintas formas de vida na terra, propiciando aos alunos tecerem costuras entre os seus conhecimentos e os conhecimentos compartilhados com eles.

As oficinas, pelo olhar da professora B. trouxeram a possibilidade dos alunos manusearem e terem a vivência com o recurso solo que não teriam em outros espaços, além de trazer para o campo da pesquisa acadêmica a importância da inclusão de todos os públicos na temática ambiental ,uma vez que pontuou o quão significativo foi a proposta da composteira por exemplo, por estar num nível de abstração mais elevado que o momento do jogo, pois os alunos demonstravam 
interesse em falar sobre o cuidado que estavam tendo com aa minhocas e o "enriquecimento do solo.

Ao olhar da professora E., a oficina da composteira recebeu destaque pois despertou nos alunos o interesse pelo cuidado com os animais e o interesse pela temática abordada uma vez que iam e voltavam com frequência ao assunto. Esse momento também foi ao encontro da proposta referente ao dia mães em que os alunos usaram o solo com minhocas para adubar as plantas que seriam utilizadas como presente para as mães da turma. A proposta da composteira também agregou um importante elemento, o filtro de café, muito usado por eles nas mais distintas situações em sala de aula valorizando assim as produções cotidianas.

Todas as manifestações dos diferentes momentos e oficinas vividos pelos alunos e acompanhado pelas professoras mostram a importância de compartilhar a temática ambiental nos diferentes espaços com distintos públicos e em especial neste ambiente de alunos com necessidades educativas especiais.

\section{CONSIDERAÇÕES FINAIS}

As vivências do cotidiano e o envolvimento do grupo com esse trabalho, ultrapassaram os muros da instituição quando a situação da composteira tornou-se um elemento vivo que inspirava cuidados, para além do diagnóstico em um prontuário, estiveram as pessoas com seus interesses e suas vivências contribuindo expressivamente com esse trabalho.

Cada participante envolveu-se à sua maneira com as propostas: tocando, desenhando, jogando, sentindo ou relatando situações do cotidiano. Nas conversas com os colegas e a maneira harmoniosa como acolheram as propostas, demostraram um cuidado e um interesse em conectar-se ainda mais as questões humanas e ambientais. 
Observou -se que a forma como cada um interagia com os materiais e as propostas fazia relação a uma vivência externa, de rua, entrelaçada as oficinas que participavam na instituição. Situações como: cuidar da alimentação e do habitat das minhocas (mesmo com o "fim" desse trabalho), visualizar o solo em seus diferentes usos e funções, possibilitaram ver o quanto este público alvo tem a contribuir em diferentes tempos e espaços com a educação ambiental, ain da que sejam muitas vezes privados destas informações.

Em cada período (oficinas e momentos) houve a possibilidade de apresentar o solo, seus usos e funções de forma a compartilhar questões ambientais. Nesse sentido a escuta dos alunos e a leitura de prontuários aleatórios foram essenciais ferramentas inclusivas para que esse trabalho fosse aceito.

Durante o desenrolar desse trabalho procuramos contornar as nossas deficiências formativas, à medida que nos propomos a ouvir os conhecimentos prévios de cada aluno, sem saber o CID delas. Essa escuta sensível foi fundamental para que o desenvolvimento das oficinas partindo de interesses comuns do grupo. Assim esse trabalho se consolidou, demonstrando o quanto essas pessoas, por vezes esquecidas pela sociedade, podem participar ativamente enquanto formadores em educação ambiental.

\section{REFERÊNCIAS BIBLIOGRÁFICAS}

BOGDAN, R.; BIKLEN, S. Investigação qualitativa em educação: uma introdução à teoria e aos métodos. Portugal: Porto Editora, 1994.

CANEPELLE, E.; KERKHOFF, J. T.; WRITZL T.C.; STEIN J. E. S.; SILVA, D. M.; REDIN, M. Ciência do solo nas escolas de ensino fundamental e médio. Revista Brasileira de Agropecuária Sustentável (RBAS), v.8, n.3, p.41-50, setembro, 2018.

CAPECHE, C. L. Educação ambiental tendo o solo como material didático: pintura com tinta de solo e colagem de solo sobre superfícies /CAPECHE, C. L.. - Dados eletrônicos. - Rio de Janeiro: Embrapa Solos, 2010. 60 p. - (Documentos / Embrapa Solos, ISSN 15172627; 123) 
DALMOLIN, R.S.D., TEN CATEN, A. Mapeamento Digital: nova abordagem em levantamento de solos. Investig. Agrar.2015; 17(2):7786. doi: 10.18004/investig.agrar.2015. diciembre. -86.

DALMOLIN, R.S.D.; PEDRON, F.A.; FRANCO, A. M. P. Solos: Base para a Sustentação da Vida. In: Paulo Piquini. (Org.). Jornada Acadêmica Integrada: compilação de artigos de 2015. Iled.Santa Maria: FACOS UFSM, 2018, v. 1, p. 63-87.

DONATO, C. A teatralidade das danças populares brasileiras e suas possíveis releituras contemporâneas: a busca por uma pedagogia da afetividade. Rio de Janeiro: ISERJ, 2012

GIL, A. C. Métodos e técnicas de pesquisa social. 6. ed. São Paulo: Atlas, 2008.

KISHIMOTO, T. M. Jogo, brinquedo, brincadeira e a educação. 14 ed. São Paulo: Cortez, 2011.

MUGGLER, C. C., PINTO, F. de A.; MACHADO, A. A. Educação em solos: princípios, teoria e métodos. Revista Brasileira de Ciência do Solo. v. 30, p. 733-740, 2006.

OLIVEIRA, A. N. S.; MARQUES, J. D. O.; PAES, Lucilene da Silva. Percepção ambiental sobre sustentabilidade do solo. EDUCERE - Revista da Educação, Umuarama, v. 17, n. 1, p. 93120, jan./jun. 2017.

OLIVEIRA, S. de F. VIANA, R. M. e PEREIRA, M. V. Educação Ambiental: pertencer e cuidar da teia da vida. Mercator - Revista de Geografia da UFC. Ano 7. n. 13. Goiânia, 2008. p. 39-46.

PEREIRA, R. T. A.; BENATI, K. R. O estudo da Educação Ambiental com Práticas Pedagógicas nas escolas: um olhar para os desafios encontrados. Rev. Monogr. Ambient. Santa Maria v.18, e8, p. 01-07, 2019. DOI:10.5902/2236130838756.

PERES, M. C. L.; BENATI, K. R.; SILVA, P. M. S.; AMORIM, V. E. P.; DIAS, M. A. Sensibilização de alunos do ensino fundamental a partir de práticas ambientais no Parque Metropolitano de Pituaçu. Rev. Monogr. Ambient. Santa Maria, v. 17, e11, p. 1-8, 2018.

SANTOS, O.; BENEVIDES, A., A. Educação em Solo: investigação em uma escola de campo. Curitiba, XII Congresso Nacional de Educação: Educere, out. 2015.

VALLADARES, L. Os dez mandamentos da observação participante. Rev. bras. Ci. Soc. vol.22 no.63 São Paulo Feb. 2007. http://dx.doi.org/10.1590/S0102-69092007000100012.

VYGOTSKY, L.S. Psicologia da Arte. São Paulo: Martins Fontes, 2004. 
Weber, M.A.; FRANÇA, J.S.; FELIPPE, B.M.; FLORES, J.M.; LORENTZ, L.H.; VIEIRA, F.C.B. Ferramentas úteis para o aprendizado em solos de estudantes do quarto ano do ensino fundamental. Experiências em Ensino de Ciências V.12, No.3. 2017. 